\title{
Associations of the serum long-chain n-3 PUFA and hair mercury with resting heart rate, peak heart rate during exercise and heart rate recovery after exercise in middle-aged men
}

\author{
Behnam Tajik $^{1}$, Sudhir Kurl ${ }^{1}$, Tomi-Pekka Tuomainen ${ }^{1}$, Kai Savonen ${ }^{2,3}$ and Jyrki K. Virtanen ${ }^{1 *}$ \\ ${ }^{1}$ Institute of Public Health and Clinical Nutrition, University of Eastern Finland, 70211 Kuopio, Finland \\ ${ }^{2}$ Kuopio Research Institute of Exercise Medicine, 70100 Kuopio, Finland \\ ${ }^{3}$ Department of Clinical Physiology and Nuclear Medicine, Kuopio University Hospital, 70029 KYS, Finland \\ (Submitted 17 July 2017 - Final revision received 29 September 2017 - Accepted 20 October 2017-First published online 5 December 2017)
}

\section{Abstract}

Long-chain $n$-3 PUFA from fish have been associated with lower risk of CVD. Fish may also contain methylmercury, which may attenuate the inverse associations of the long-chain $n$-3 PUFA. However, the mechanisms underlying these associations are not fully known. We evaluated the associations of the serum long-chain $n-3$ PUFA (EPA, DPA and DHA) and hair Hg with resting heart rate (HR), peak HR during cycle ergometer exercise and HR recovery after exercise. A total of 1008 men from the population-based Kuopio Ischaemic Heart Disease Risk Factor Study, aged 42-60 years and free of CVD, were studied. After multivariate-adjustments in ANCOVA, higher serum total long-chain $n$-3 PUFA concentration was associated with lower resting HR (extreme-quartile difference $2 \cdot 2$ beats $/$ min; $95 \%$ CI $0 \cdot 2$, 4.1, $P_{\text {trend }}$ across quartiles $=0.02$ ), but not with peak HR or HR recovery. Associations were generally similar when EPA, DPA and DHA were evaluated individually, except for DPA, which was also associated with better HR recovery after exercise (extreme-quartile difference $2 \cdot 1$ beats/min; $95 \%$ CI $0 \cdot 1,4 \cdot 2, P_{\text {trend }}=0 \cdot 06$ ). Higher hair $\mathrm{Hg}$ content had a trend towards lower peak HR after adjusting for the long-chain $n$-3 PUFA $\left(P_{\text {trend }}=0.05\right)$, but it only slightly attenuated the associations of the serum long-chain $n-3$ PUFA with HR. These findings suggest that higher serum long-chain $n-3$ PUFA concentrations are associated with lower resting HR in middle-aged men from Eastern Finland, which may partially explain the potential cardioprotective effect of fish intake.

\section{Key words: Fatty acids: Heart rate: Exercise tests: Cohort studies: Cross-sectional studies}

CVD is the leading cause of global mortality ${ }^{(1)}$. Epidemiological and clinical evidence suggests that intake of fish or the longchain $n$-3 PUFA (EPA and DHA) from fish may decrease risk of $\mathrm{CVD}^{(2,3)}$, especially fatal $\mathrm{CHD}^{(4)}$. The potential mechanisms for protection against CVD include beneficial effects on several CVD risk factors, such as blood pressure, inflammation and platelet aggregation $^{(2)}$.

In addition to these CVD risk factors, higher resting heart rate (HR) is associated with higher risk of total and cardiovascularrelated mortality ${ }^{(5,6)}$. Moreover, epidemiological studies, including the Kuopio Ischaemic Heart Disease Risk Factor Study (KIHD) from eastern Finland ${ }^{(7,8)}$, have demonstrated that a low peak HR during an exercise test ${ }^{(9)}$ and a delayed HR recovery after an exercise test ${ }^{(10)}$ are related to higher risk of CVD mortality.

Fish oil supplementation has been reported to reduce resting $\mathrm{HR}^{(11)}$, and epidemiological studies have found an inverse association between fish intake or long-chain n-3 PUFA and resting $\mathrm{HR}^{(12-17)}$. Some experimental studies have also investigated the impact of fish oil supplementation on the peak
HR during an exercise test and on HR recovery after an exercise test, with inconsistent findings ${ }^{(18-25)}$. To the best of our knowledge, there is no published data from population studies about the association of the long-chain $n$ - 3 PUFA with peak HR during exercise and HR recovery after exercise.

In addition to the long-chain $n-3$ PUFA, fish, especially large and long-living predatory fish, may accumulate methylmercury, an environmental contaminant ${ }^{(26)}$. Methylmercury has been associated with higher risk of CVD and with attenuation of the cardioprotective benefits of the long-chain $n$-3 PUFA, especially in the KIHD cohort ${ }^{(27-29)}$, but also in other study populations ${ }^{(30)}$. Methylmercury is a neurotoxicant, and the autonomic function of the heart is governed by the central nervous ${ }^{(26)}$. Only a few epidemiological studies have evaluated the association of methylmercury exposure with resting HR, with divergent results ${ }^{(31-35)}$. However, very little is known whether exposure to methylmercury has an association with HR during and after exercise.

In order to elucidate the relations of the long-chain $n$-3 PUFA with resting and exercise-related $\mathrm{HR}$ and $\mathrm{HR}$ recovery, we

Abbreviations: HR, heart rate; KIHD, Kuopio Ischaemic Heart Disease Risk Factor Study.

* Corresponding author: J. K. Virtanen, fax +358 17 162936, email jyrki.virtanen@uef.fi 
investigated the cross-sectional associations of the serum longchain $n$-3 PUFA with resting HR, peak HR during an exercise test and HR recovery after an exercise test among generally healthy middle-aged and older men from the population-based KIHD cohort. We also evaluated whether high hair $\mathrm{Hg}$ concentration, a biomarker for long-term $\mathrm{Hg}$ exposure, is associated with these outcomes and whether it could modify the associations with the long-chain $n$ - 3 PUFA

\section{Methods \\ Study population}

We performed a cross-sectional analysis among the participants from the KIHD cohort, a population-based study designed to investigate risk factors for CVD, atherosclerosis, and related outcomes in men from eastern Finland ${ }^{(36)}$. A total of 2682 men ( $82.9 \%$ of those eligible) who were $42,48,54$ or 60 years old and living in the city of Kuopio or its surrounding areas were recruited to the baseline examinations in 1984-1989. The baseline characteristics of the entire study population have been described previously ${ }^{(36)}$. The KIHD protocol was approved by the Research Ethics Committee of the University of Eastern Finland and complies with the Declaration of Helsinki. All the subjects signed a written informed consent.

From the analyses we excluded participants with a history of CVD ( $n$ 1016), those using beta-blockers ( $n$ 135) and those with missing data on HR parameters ( $n$ 435), serum long-chain $n$-3 PUFA ( $n$ 78) or hair Hg ( $n$ 9). We also exclude one participant with resting $\mathrm{HR}$ outside of the nomogram range $(\mathrm{HR}<30$ or HR $>130$ beats/min). After the exclusions, the final study population included 1008 men (online Supplementary Fig. 1).

\section{Assessment of heart rate parameters and other exercise test variables}

A maximal, symptom-limited exercise test was performed at baseline using an electrically braked cycle ergometer, as described previously ${ }^{(37,38)}$. The primary aim was to explore HR data from rest to maximal workload systematically instead of using arbitrarily chosen parts of recorded HR data. HR was recorded from an electrocardiogram (ECG) at rest, at the end of each 60-s interval during the exercise test, at peak exercise and during recovery. Resting HR was expressed as the lowest HR value, whether measured in lying position before the test or while sitting on bicycle at the initiation of the test. During recovery, the workload was set to $0 \mathrm{~W}$ and subjects were allowed to continue pedaling at a self-chosen frequency if desired. No predefined pedaling frequency was used during recovery. HR recovery was defined a priori as the reduction in HR from HR peak to HR at 2 min after the exercise test to maximise the number of subjects included in the analyses, because values of HR at 1 min after the exercise test were not available for all men.

\section{Other measurements}

Hair and venous blood samples were obtained between 08.00 and 10.00 hours after having abstained from ingesting alcohol for $3 \mathrm{~d}$, smoking for $12 \mathrm{~h}$, and eating for $12 \mathrm{~h}$. After the subject had rested in the supine position for $30 \mathrm{~min}$, blood was drawn with Terumo Venoject VT-100PZ vacuum (Terumo Corp.). No tourniquet was used. A hair sample averaging $40 \mathrm{mg}$ was cut from the scalp hair of the subjects for $\mathrm{Hg}$ measurements ${ }^{(39)}$.

Comprehensive description of the determination of serum lipids and lipoproteins, assessment of medical history and medications, smoking and alcohol consumption have been reported previously ${ }^{(40)}$. Physical activity was evaluated based on the 12-month leisure-time physical activity questionnaire and expressed as $\mathrm{kJ} / \mathrm{d}(\mathrm{kcal} / \mathrm{d})^{(37)}$. The most common leisuretime physical activities were recorded, including the average duration, intensity and frequency of each activity. Hypertension diagnosis was defined as systolic/diastolic blood pressure $>140 / 90 \mathrm{mmHg}$ at study visit, clinical diagnosis of hypertension or use of hypertension medication ${ }^{(41)}$. Dietary intakes of foods and nutrients were assessed at the time of blood sampling with an instructed 4 -d food diary by household measures ${ }^{(42)}$. The instructions were given and the completed food records were checked by a nutritionist. Education and annual income were assessed by using self-administered questionnaires.

\section{Serum fatty acid and mercury measurements}

Serum fatty acids were determined in one gas chromatographic run without preseparation as described previously ${ }^{(43)}$. Serum fatty acids were extracted with chloroform-methanol. Chloroform phase was evaporated and treated with sodium methoxide, which methylated esterified fatty acids. Quantification was carried out with reference standards (Check Prep Inc.). Each analyte had individual reference standard, and an internal standard was eicosane. Fatty acids were chromatographed in an NB-351 capillary column (HNU-Nordion) by a Hewlett-Packard 5890 Series II gas chromatograph (Hewlett-Packard Company, since 1999 Agilent Technologies Inc.) with a flame ionization detector. Results were obtained in micromoles per litter and in the data analyses proportion of a fatty acid from the total serum fatty acids was used. The CV was $9.4 \%$ for EPA (20:5n-3), $12.7 \%$ for DPA $(22: 5 n-3)$ and $11.9 \%$ for DHA (22:5n-3). For the serum total long-chain $n$-3 PUFA, we used the sum of EPA, DPA and DHA.

Hair $\mathrm{Hg}$ was detected by flow injection analysis-cold vapour atomic absorption spectrometry and amalgamation ${ }^{(39)}$. Repeat hair samples were collected from twenty-one subjects in 4 to 9 years (mean, 6 years) after baseline examination to survey the tracking of hair $\mathrm{Hg}$ values over time. Pearson's correlation coefficient between the original and the repeat measurement was $0 \cdot 91$.

\section{Statistical analysis}

The univariate associations between the serum total long-chain $n$-3 PUFA (EPA + DPA + DHA) concentration and demographic, lifestyle and clinical characteristics at baseline were assessed by linear regression for continuous variables and $\chi^{2}$ test for categorical variables. Correlations between the individual longchain $n$-3 PUFA were evaluated by Spearman correlation coefficients. The mean values of resting HR, peak HR during 
exercise and HR recovery 2 min after exercise in the quartiles of the long-chain $n$-3 PUFA and hair $\mathrm{Hg}$ were analysed using ANCOVA, adjusted for potential confounders. The model 1 was adjusted for age (years) and examination year. The model 2 included the variables in the model 1 plus BMI $\left(\mathrm{kg} / \mathrm{m}^{2}\right)$, type 2 diabetes (yes/no), smoking status (never smoker, previous smoker, current smoker $<20$ cigarettes/d and current smoker $\geq 20$ cigarettes $/ \mathrm{d})$, leisure-time physical activity $(\mathrm{kJ} / \mathrm{d}(\mathrm{kcal} / \mathrm{d})$ ), education (years), income (euro), hypertension (yes/no), fasting blood glucose $(\mathrm{mmol} / \mathrm{l})$, energy intake $(\mathrm{kJ} / \mathrm{d}(\mathrm{kcal} / \mathrm{d}))$, and alcohol intake ( $\mathrm{g} /$ week). Additional adjustments for serum TAG, HDL- or LDL-cholesterol concentrations, lipid-lowering medication use or maximal oxygen uptake during the exercise test, did not appreciably change the associations ( $<5 \%$ change in estimates).

Cohort mean was used to replace missing values in covariates $(<0.5 \%)$. Tests of linear trend across categories were conducted by assigning the median values for each category of exposure variable and treating those as a single continuous variable. To assess clinical significance of the findings, we calculated effect sizes based on the Cohen's $d$ index (the difference between the group means divided by the standard deviation of the comparison category) ${ }^{(44)}$. All $P$ values were two-sided $(\alpha \leq 0.05)$. Data were analysed using the SPSS software version 23 for Windows (IBM Corp.).

\section{Results}

\section{Baseline characteristics}

The mean age of the participant was 51.4 (SD 5.7) years. The mean serum concentrations, as a percentage of all serum fatty acids, were 4.71 (SD 1.57 ) \% for serum total long-chain $n$-3 PUFA concentration, 2.48 (SD 0.71) \% for DHA, 1.67 (SD 0.89) \% for EPA and 0.56 (SD 0.10$) \%$ for DPA. The correlations between the individual long-chain $n$-3 PUFA were 0.70 for EPA and DHA, 0.56 for EPA and DPA, and 0.41 for DHA and DPA. Baseline characteristics of the participants according to quartiles of the total long-chain $n-3$ PUFA concentration are presented in the Table 1. Men with higher concentration were more likely to have a higher annual income, BMI, fasting blood glucose, hair $\mathrm{Hg}$ concentration and alcohol intake. They also had a lower energy intake.

\section{Associations with resting heart rate}

The mean resting HR was 68.2 beats/min. In the multivariableadjusted model, higher serum total long-chain $n-3$ PUFA concentration was associated with lower resting $\mathrm{HR}$ (the mean difference between the highest and the lowest quartile $-2 \cdot 17$ beats $/ \mathrm{min} ; 95 \% \mathrm{CI}-4 \cdot 10,-0 \cdot 24, P_{\text {for trend }}=0.02$ across quartiles), model 2, Table 2). When the fatty acids were investigated individually, generally similar inverse associations were observed with EPA, DPA and DHA, although the association with EPA appeared slightly stronger than those with DPA and DHA (Table 2). The effect sizes, based on Cohen's $d$ index, were 0.12 for total serum long-chain $n$-3 PUFA, 0.07 for EPA, $0 \cdot 10$ for DPA, $0 \cdot 14$ for DHA.
Hair $\mathrm{Hg}$ concentration was not statistically significantly associated with resting HR (Table 2). Additional adjustment of the fatty acid analyses for hair $\mathrm{Hg}$ content only slightly attenuated the associations (model 3, Table 2).

\section{Associations with peak heart rate during an exercise test}

The mean peak HR during the exercise test was 164.8 beats/ min. Serum total long-chain $n$-3 PUFA concentration or the individual fatty acids were not associated with the peak HR (Table 3). After adjustment for age and examination year, higher hair $\mathrm{Hg}$ content was associated with lower peak HR during an exercise test (the mean difference between extreme quartiles -3.55 beats $/ \mathrm{min}$; $95 \% \mathrm{CI}-6 \cdot 25,-0 \cdot 85, P_{\text {for trend }}=0.001$ across quartiles), model 1, Table 3; Cohen's $d=0 \cdot 10$ ).

Further adjustments slightly attenuated the association (model 2), but there was again a trend towards lower peak HR after the serum long-chain $n$-3 PUFA concentration was adjusted for $(P=0.05$ for trend across quartiles, model 3, Table 3).

\section{Associations with 2-min heart rate recovery}

The mean HR recovery $2 \mathrm{~min}$ after the exercise test was $40 \cdot 6$ beats. We did not observe an association between the serum total long-chain $n-3$ PUFA concentration and 2-min HR recovery. Of the individual fatty acids, only DPA was associated with better HR recovery (the mean difference between extreme quartiles 3.57 beats; 95\% CI 1.52, 5.62, $P_{\text {for trend }}=0.001$ across quartiles), model 1, Table 4; Cohen's $d=0 \cdot 11$ ).

Further adjustment for the potential confounders (model 2) and hair $\mathrm{Hg}$ (model 3) slightly attenuated the association. Hair $\mathrm{Hg}$ concentration was not associated with $\mathrm{HR}$ recovery (Table 4).

\section{Discussion}

In this study among 1008 generally healthy middle-aged and older men from Eastern Finland, higher serum total long-chain $n$-3 PUFA concentration was associated with lower resting HR. Generally similar associations with resting HR were observed with the individual long-chain $n$-3 PUFA EPA, DPA and DHA, although the associations with EPA appeared slightly stronger. No associations were observed with peak HR during exercise or HR recovery after exercise, except for a borderline statistically significant association between serum DPA and better 2-min HR recovery. However, the clinical significance of these associations was quite modest. Hair $\mathrm{Hg}$ content was associated with lower peak HR and it only slightly attenuated the associations of the serum long-chain $n$-3 PUFA.

Previously in this study population, higher serum long-chain $n$-3 PUFA concentration has been inversely associated with risk of $\mathrm{CVD}^{(27,29)}$ and with CVD risk factors, including C-reactive protein $^{(45)}$, high blood pressure ${ }^{(46)}$, prolonged QT- and JT intervals $^{(47)}$, and low exercise cardiac power ${ }^{(48)}$.

In the present study, we found that higher serum long-chain $n-3$ PUFA concentrations were inversely associated with resting HR. The extreme-quartile mean difference was $2 \cdot 2$ beats/min. 
Table 1. Baseline characteristics according to serum total long-chain $n-3$ PUFA*

(Mean values and standard deviations; percentages)

\begin{tabular}{|c|c|c|c|c|c|c|c|c|c|}
\hline \multirow[b]{3}{*}{ Variables } & \multicolumn{9}{|c|}{ Serum total long-chain $n$-3 PUFA quartile (\%) } \\
\hline & \multicolumn{2}{|c|}{$\begin{array}{c}\text { Q1 } \\
(<3 \cdot 26, n \text { 252) }\end{array}$} & \multicolumn{2}{|c|}{$\begin{array}{c}\text { Q2 } \\
(3.26-4.01 \%, n 252)\end{array}$} & \multicolumn{2}{|c|}{$\begin{array}{c}\text { Q3 } \\
(4 \cdot 01-4.78 \%, n 252)\end{array}$} & \multicolumn{2}{|c|}{$\begin{array}{c}\text { Q4 } \\
(>4.78, n 252)\end{array}$} & \multirow[b]{2}{*}{$P_{\text {for trend }}$} \\
\hline & Mean & SD & Mean & SD & Mean & SD & Mean & SD & \\
\hline Age (years) & $50 \cdot 9$ & $5 \cdot 9$ & $51 \cdot 7$ & $5 \cdot 6$ & $51 \cdot 3$ & $5 \cdot 6$ & $51 \cdot 7$ & $5 \cdot 6$ & 0.24 \\
\hline Education (years) & $9 \cdot 3$ & 3.4 & $8 \cdot 8$ & 3.6 & $8 \cdot 8$ & 3.5 & 9.6 & 3.9 & 0.16 \\
\hline Annual income $(€)$ & 13773 & 7147 & 14186 & 9794 & 15104 & 10791 & 15867 & 9280 & 0.01 \\
\hline BMI $\left(\mathrm{kg} / \mathrm{m}^{2}\right)$ & $26 \cdot 2$ & 3.4 & 26.5 & 3.2 & $26 \cdot 6$ & 3.2 & $26 \cdot 8$ & 3.3 & 0.05 \\
\hline Height (cm) & 173.8 & $6 \cdot 3$ & $173 \cdot 1$ & $6 \cdot 0$ & 173.3 & $6 \cdot 1$ & 173.4 & $5 \cdot 6$ & 0.72 \\
\hline Weight $(\mathrm{kg})$ & $79 \cdot 1$ & 11.5 & 79.6 & 11.0 & 80.0 & 11.6 & $80 \cdot 7$ & 11.4 & 0.11 \\
\hline Physical activity (kJ/d) & 628 & 774 & 527 & 628 & 573 & 602 & 623 & 711 & 0.69 \\
\hline Physical activity (kcal/d) & 150 & 185 & 126 & 150 & 137 & 144 & 149 & 170 & \\
\hline Blood glucose (mmol/l) & 4.65 & 0.86 & 4.57 & 0.63 & 4.73 & 0.88 & 4.76 & 0.95 & 0.03 \\
\hline Energy intake $(\mathrm{kJ} / \mathrm{d})$ & 10443 & 3017 & 10242 & 2531 & 10008 & 2674 & 9715 & 2502 & 0.001 \\
\hline Energy intake (kcal/d) & 2496 & 721 & 2448 & 605 & 2392 & 639 & 2322 & 598 & \\
\hline Alcohol intake (g/week) & 58.4 & $90 \cdot 3$ & 66.5 & 98.8 & $81 \cdot 3$ & 128.5 & 89.0 & $125 \cdot 5$ & 0.001 \\
\hline Current smoker (\%) & \multicolumn{2}{|c|}{32} & \multicolumn{2}{|c|}{31} & \multicolumn{2}{|c|}{30} & \multicolumn{2}{|c|}{31} & 0.75 \\
\hline Diabetes (\%) & \multicolumn{2}{|c|}{4} & \multicolumn{2}{|c|}{3} & \multicolumn{2}{|c|}{4} & \multicolumn{2}{|c|}{4} & 0.95 \\
\hline Hypertension (\%) & \multicolumn{2}{|c|}{47} & \multicolumn{2}{|c|}{49} & \multicolumn{2}{|c|}{49} & \multicolumn{2}{|c|}{47} & 0.98 \\
\hline Serum EPA (\%)† & 0.96 & 0.23 & $1 \cdot 29$ & 0.24 & 1.66 & 0.27 & $2 \cdot 75$ & $1 \cdot 10$ & $<0.001$ \\
\hline Serum DPA (\%)† & 0.48 & 0.07 & 0.53 & 0.07 & 0.57 & 0.80 & 0.64 & 0.11 & $<0.001$ \\
\hline Serum DHA (\%)† & $1 \cdot 76$ & 0.28 & $2 \cdot 19$ & 0.26 & 2.59 & 0.28 & $3 \cdot 39$ & 0.62 & $<0.001$ \\
\hline Hair $\mathrm{Hg}(\mu \mathrm{g} / \mathrm{g})$ & 1.09 & 1.31 & $1 \cdot 70$ & 1.92 & $2 \cdot 01$ & 1.99 & $2 \cdot 74$ & 2.50 & $<0.001$ \\
\hline
\end{tabular}

$Q$, quartiles.

* The univariate associations between the serum total long-chain $n$-3 PUFA concentration and demographic, lifestyle and clinical characteristics at baseline were assessed by linear regression for continuous variables and $x^{2}$-test for categorical variables.

† Proportion of all serum fatty acids.

Table 2. Resting heart rate (beats per min) in quartiles of serum long-chain $n$-3 PUFA and hair mercury among 1008 men aged $42-60$ years from the Kuopio Ischaemic Heart Disease Risk Factor Study*

(Mean values and $95 \%$ confidence intervals)

\begin{tabular}{|c|c|c|c|c|c|c|c|c|c|}
\hline & \multicolumn{6}{|c|}{ Exposure quartile } & \multirow[b]{3}{*}{$P_{\text {for trend }}$} & \multirow{2}{*}{\multicolumn{2}{|c|}{$\begin{array}{l}\text { Difference between the highest } \\
\text { and lowest quartile }\end{array}$}} \\
\hline & \multicolumn{2}{|c|}{$1(n 252)$} & \multirow[b]{2}{*}{$2(n 252)$} & \multirow[b]{2}{*}{$3(n$ 252) } & \multicolumn{2}{|c|}{$4(n 252)$} & & & \\
\hline & Mean & $95 \% \mathrm{Cl}$ & & & Mean & $95 \% \mathrm{Cl}$ & & Mean & $95 \% \mathrm{Cl}$ \\
\hline Total long-chain n-3 PUFA (\%) & & $3 \cdot 26 \dagger$ & $3 \cdot 26-4 \cdot 01$ & $4 \cdot 01-4 \cdot 78$ & & 4.78 & & & \\
\hline Model $1 \ddagger$ & 68.4 & $67 \cdot 0,69 \cdot 8$ & $68 \cdot 6$ & $68 \cdot 9$ & $66 \cdot 9$ & $65.5,69.7$ & $0 \cdot 10$ & -1.51 & $-3.48,0.45$ \\
\hline Model $2 \S$ & $68 \cdot 7$ & $67 \cdot 4,70 \cdot 1$ & $68 \cdot 8$ & $68 \cdot 7$ & $66 \cdot 5$ & $65 \cdot 2,67 \cdot 9$ & 0.02 & $-2 \cdot 17$ & $-4 \cdot 10,-0.24$ \\
\hline Model 3॥ & $68 \cdot 6$ & $67 \cdot 3,70 \cdot 3$ & $68 \cdot 7$ & $68 \cdot 7$ & $66 \cdot 6$ & $65 \cdot 2,68 \cdot 0$ & 0.04 & $-2 \cdot 01$ & $-4.02,0.01$ \\
\hline EPA (\%) & & 0.94 & $0.94-1.27$ & $1 \cdot 27-1 \cdot 66$ & & 1.66 & & & \\
\hline Model 1‡ & $69 \cdot 2$ & $67 \cdot 8,70 \cdot 6$ & $68 \cdot 6$ & $68 \cdot 4$ & $66 \cdot 7$ & $65 \cdot 3,68 \cdot 1$ & 0.01 & -2.49 & $-4.49,0.50$ \\
\hline Model $2 \S$ & $69 \cdot 4$ & $68 \cdot 1,70 \cdot 8$ & $68 \cdot 9$ & 68.4 & $66 \cdot 0$ & $64 \cdot 7,67 \cdot 4$ & $<0.001$ & $-3 \cdot 40$ & $-5 \cdot 35,-1.46$ \\
\hline Model 3॥ & $69 \cdot 4$ & $68.0,70.7$ & 68.9 & 68.4 & $66 \cdot 1$ & $64 \cdot 7,67 \cdot 5$ & 0.001 & $-3 \cdot 34$ & $-5 \cdot 36,-1 \cdot 32$ \\
\hline DPA (\%) & & 0.45 & $0.45-0.52$ & $0.52-0.58$ & & 0.58 & & & \\
\hline Model 1f & $70 \cdot 4$ & $69 \cdot 0,71 \cdot 7$ & 68.5 & $67 \cdot 2$ & $66 \cdot 7$ & $65 \cdot 4,68 \cdot 1$ & 0.001 & $-3 \cdot 61$ & $-5 \cdot 56,-1.66$ \\
\hline Model $2 \S$ & $69 \cdot 7$ & $68 \cdot 3,71 \cdot 1$ & $68 \cdot 3$ & $67 \cdot 6$ & $67 \cdot 2$ & $65 \cdot 8,68.5$ & 0.01 & $-2 \cdot 52$ & $-4.46,-0.59$ \\
\hline Model 3॥ & $69 \cdot 6$ & $68 \cdot 2,71 \cdot 0$ & $68 \cdot 3$ & $67 \cdot 6$ & $67 \cdot 2$ & $65.9,68.6$ & 0.02 & $-2 \cdot 38$ & $-4.35,-0.42$ \\
\hline DHA (\%) & & $1 \cdot 73$ & $1 \cdot 73-2 \cdot 19$ & $2 \cdot 19-2.59$ & & $2 \cdot 59$ & & & \\
\hline Model 1‡ & $68 \cdot 5$ & $67 \cdot 1,69 \cdot 8$ & 68.5 & 68.6 & $67 \cdot 2$ & $65 \cdot 8,68.5$ & 0.18 & $-1 \cdot 30$ & $-3.26,0.66$ \\
\hline Model $2 \S$ & $68 \cdot 8$ & $67 \cdot 4,70 \cdot 2$ & $68 \cdot 6$ & $68 \cdot 4$ & $66 \cdot 9$ & $65 \cdot 5,68 \cdot 3$ & 0.05 & -1.83 & $-3.78,0.10$ \\
\hline Model 3॥ & $68 \cdot 7$ & $67 \cdot 3,70 \cdot 1$ & 68.5 & $68 \cdot 4$ & $67 \cdot 1$ & $65 \cdot 7,68 \cdot 5$ & 0.09 & -1.62 & $-3.65,0.41$ \\
\hline Hair Hg $(\mu \mathrm{g} / \mathrm{g})$ & & 0.36 & $0.36-0.91$ & $0.91-1.68$ & & 1.68 & & & \\
\hline Model $1 \mp$ & $67 \cdot 8$ & $66 \cdot 4,69 \cdot 2$ & $69 \cdot 0$ & $68 \cdot 3$ & $67 \cdot 6$ & $66 \cdot 2,69 \cdot 0$ & 0.46 & -0.25 & $-2 \cdot 27,1 \cdot 77$ \\
\hline Model $2 \S$ & $68 \cdot 2$ & $66 \cdot 8,69 \cdot 6$ & $69 \cdot 1$ & $68 \cdot 5$ & $67 \cdot 0$ & $65 \cdot 6,68 \cdot 4$ & 0.10 & $-1 \cdot 24$ & $-3.24,0.76$ \\
\hline Model 3॥ & $67 \cdot 8$ & $66 \cdot 4,69 \cdot 2$ & $69 \cdot 0$ & $68 \cdot 5$ & $67 \cdot 4$ & $66 \cdot 0,68.9$ & 0.36 & -0.39 & $-2.53,1.74$ \\
\hline
\end{tabular}

* The association of serum long-chain $n-3$ PUFA and hair $\mathrm{Hg}$ with resting heart rate was analysed using ANCOVA.

$\dagger$ Medians.

¥ Model 1 is adjusted for age and examination year.

$\S$ Model 2 is adjusted for model $1+\mathrm{BMI}\left(\mathrm{kg} / \mathrm{m}^{2}\right.$ ), diabetes (yes/no), hypertension (yes/no), smoking (yes/no), education (years), income (euro), leisure-time physical activity $(\mathrm{kJ} /$ week (kcal/week)), intake of alcohol ( $\mathrm{g} /$ week), energy intake $(\mathrm{kJ} / \mathrm{d}(\mathrm{kcal} / \mathrm{d}))$ and blood glucose (mmol/l).

II Model 3 is adjusted for model $2+$ hair $\mathrm{Hg}$ (in analyses with fatty acids) or total long-chain $n$-3 PUFA (in analyses with $\mathrm{Hg}$ ). 
Table 3. Peak heart rate (beats per min) during an exercise test in quartiles of serum long-chain $n-3$ PUFA and hair mercury among 1008 men aged $42-60$ years from Kuopio Ischaemic Heart Disease Risk Factor Study*

(Mean values and $95 \%$ confidence intervals)

\begin{tabular}{|c|c|c|c|c|c|c|c|c|c|}
\hline & \multicolumn{6}{|c|}{ Exposure quartile } & \multirow[b]{3}{*}{$P_{\text {for trend }}$} & \multirow{2}{*}{\multicolumn{2}{|c|}{$\begin{array}{l}\text { Difference between the highest } \\
\text { and lowest quartile }\end{array}$}} \\
\hline & \multicolumn{2}{|r|}{$1(n 252)$} & \multirow[b]{2}{*}{$2(n 252)$} & \multirow[b]{2}{*}{$3(n 252)$} & \multicolumn{2}{|c|}{$4(n 252)$} & & & \\
\hline & Mean & $95 \% \mathrm{Cl}$ & & & Mean & $95 \% \mathrm{Cl}$ & & Mean & $95 \% \mathrm{Cl}$ \\
\hline Total long-chain $n$-3 PUFA (\%) & & $<3.26 \dagger$ & $3.26-4.01$ & $4 \cdot 01-4 \cdot 78$ & & $>4.78$ & & & \\
\hline Model $1 \ddagger$ & $165 \cdot 0$ & $163 \cdot 1,166 \cdot 8$ & 164.7 & $165 \cdot 2$ & 164.5 & $162 \cdot 6,166 \cdot 4$ & 0.77 & -0.47 & $-3 \cdot 12,2 \cdot 18$ \\
\hline Model $2 \S$ & 164.9 & $163 \cdot 1,166 \cdot 7$ & $164 \cdot 8$ & $165 \cdot 2$ & 164.5 & $162 \cdot 7,166 \cdot 3$ & 0.86 & -0.38 & $-2 \cdot 96,2 \cdot 20$ \\
\hline Model 3॥ & 164.9 & $163 \cdot 1,166 \cdot 7$ & 164.7 & $165 \cdot 2$ & 164.6 & $162 \cdot 7,166 \cdot 4$ & 0.82 & -0.31 & $-3 \cdot 0,2 \cdot 39$ \\
\hline EPA (\%) & & $<0.94$ & $0.94-1.27$ & $1.27-1.66$ & & $>1.66$ & & & \\
\hline Model 1‡ & 164.4 & $162 \cdot 5,166 \cdot 3$ & $166 \cdot 1$ & $165 \cdot 3$ & $163 \cdot 6$ & $161 \cdot 7,165 \cdot 4$ & 0.26 & -0.86 & $-3.55,1.83$ \\
\hline Model $2 \S$ & $164 \cdot 3$ & $162 \cdot 4,166 \cdot 1$ & $165 \cdot 8$ & 165.5 & 163.9 & $162 \cdot 1,165 \cdot 7$ & 0.51 & -0.36 & $-2 \cdot 96,2 \cdot 25$ \\
\hline Model 3॥ & $164 \cdot 3$ & $162 \cdot 4,166 \cdot 1$ & $165 \cdot 8$ & $165 \cdot 5$ & 163.9 & $162 \cdot 0,165 \cdot 7$ & 0.54 & -0.34 & $-3.05,2.36$ \\
\hline DPA (\%) & & $<0.45$ & $0.45-0.52$ & $0.52-0.58$ & & $>0.58$ & & & \\
\hline Model 1‡ & 163.7 & $161 \cdot 9,165 \cdot 6$ & 163.9 & $165 \cdot 8$ & 165.9 & $164 \cdot 0,167 \cdot 7$ & 0.06 & $2 \cdot 14$ & $-0.50,4.78$ \\
\hline Model $2 \S$ & 164.6 & $162 \cdot 8,166 \cdot 5$ & $164 \cdot 1$ & $165 \cdot 2$ & $165 \cdot 3$ & $163 \cdot 5,167 \cdot 1$ & 0.45 & 0.71 & $-1.88,3.30$ \\
\hline Model 3॥ & 164.6 & $162 \cdot 8,166 \cdot 4$ & $164 \cdot 1$ & $165 \cdot 3$ & $165 \cdot 4$ & $163 \cdot 6,167 \cdot 2$ & 0.42 & 0.79 & $-1.84,3.42$ \\
\hline DHA (\%) & & $<1.73$ & $1 \cdot 73-2 \cdot 19$ & $2 \cdot 19-2.59$ & & $>2.59$ & & & \\
\hline Model 1‡ & $166 \cdot 3$ & $164 \cdot 5,168 \cdot 2$ & $163 \cdot 3$ & $164 \cdot 2$ & 165.5 & $163 \cdot 7,167 \cdot 4$ & 0.86 & -0.80 & $-3 \cdot 43,1 \cdot 84$ \\
\hline Model $2 \S$ & 166.5 & $164 \cdot 7,168 \cdot 3$ & $163 \cdot 2$ & 164.5 & $165 \cdot 1$ & $163 \cdot 3,166 \cdot 9$ & 0.63 & -1.32 & $-3 \cdot 92,1 \cdot 28$ \\
\hline Model 3॥ & 166.5 & $164 \cdot 7,168 \cdot 3$ & $163 \cdot 2$ & $164 \cdot 4$ & $165 \cdot 2$ & $163 \cdot 3,167 \cdot 0$ & 0.66 & -1.29 & $-3.99,1.41$ \\
\hline Hair Hg $(\mu \mathrm{g} / \mathrm{g})$ & & $<0.36$ & $0.36-0.91$ & $0.91-1.68$ & & $>1.68$ & & & \\
\hline Model $1 \ddagger$ & $166 \cdot 1$ & $164 \cdot 2,167.9$ & 167.5 & $163 \cdot 3$ & 162.5 & $160 \cdot 6,164 \cdot 4$ & 0.001 & -3.55 & $-6.25,-0.85$ \\
\hline Model $2 \S$ & $165 \cdot 3$ & $163 \cdot 5,167 \cdot 1$ & $166 \cdot 9$ & $163 \cdot 4$ & $163 \cdot 8$ & $161 \cdot 9,165 \cdot 6$ & 0.08 & -1.55 & $-4 \cdot 22,1 \cdot 11$ \\
\hline Model 3॥ & 165.5 & $163.6,167 \cdot 4$ & $167 \cdot 0$ & $163 \cdot 3$ & 163.5 & $161 \cdot 6,165.5$ & 0.05 & -1.99 & $-4.84,0.86$ \\
\hline
\end{tabular}

* The association of serum long-chain $n$-3 PUFA and hair $\mathrm{Hg}$ with peak heart rate was analysed using ANCOVA.

$\dagger$ Medians.

$\ddagger$ Model 1 is adjusted for age and examination year.

$\S$ Model 2 is adjusted for model $1+\mathrm{BMI}\left(\mathrm{kg} / \mathrm{m}^{2}\right)$, diabetes (yes $\left./ \mathrm{no}\right)$, hypertension (yes/no), smoking (yes/no), education (years), income (euro), leisure-time physical activity $(\mathrm{kJ} /$ week (kcal/week)), intake of alcohol ( $\mathrm{g} /$ week), energy intake $(\mathrm{kJ} / \mathrm{d}(\mathrm{kcal} / \mathrm{d}))$ and blood glucose $(\mathrm{mmol} / \mathrm{l})$.

II Model 3 is adjusted for model $2+$ hair $\mathrm{Hg}$ (in analyses with fatty acids) or total long-chain $n$-3 PUFA (in analyses with $\mathrm{Hg}$ ).

This finding is in line with several supplementation trials and observational studies. For example, according to a metaanalysis of thirty trials, fish oil supplementation $(3.5 \mathrm{~g} / \mathrm{d}$ of $\mathrm{EPA}+\mathrm{DHA})$ reduced the resting HR by 2.5 beats $/ \mathrm{min}^{(11)}$. In population-based studies, among 9758 older men, resting HR was lower in high fish consumers compared with nonconsumers $^{(12)}$. Similarly, results of two large cross-sectional studies among older adults showed that intake of fish or longchain $n$-3 PUFA from fish was inversely associated with resting $\mathrm{HR}^{(13,14)}$. An inverse association was also observed between erythrocyte concentration of long-chain $n-3$ PUFA (EPA + DHA) and resting $\mathrm{HR}$ in three small cross-sectional population-based studies among middle-aged and older women ${ }^{(16)}$ and in general populations $^{(15,17)}$.

Exploration of the mechanism underlying this inverse association is beyond the scope of the current study and future research is warranted. However, impact of the long-chain $n-3$ PUFA on cardiac autonomic regulation, reduction of sympathetic activity and enhancement of parasympathetic activity, which may lead to a lower myocyte-beating rate ${ }^{(49)}$. Other potential mechanisms include the influence of these fatty acids on the function of ion channels $\left(\mathrm{Na}^{+}\right.$and $\left.\mathrm{Ca}^{2+}\right)$ in heart cell membranes ${ }^{(50)}$.

Regular exercise and physical activity are associated with lower $\mathrm{HR}^{(51)}$ and better HR recovery ${ }^{(52)}$ and with lower risk of $\mathrm{CVD}^{(53)}$. However, in this study population higher serum longchain $n$-3 PUFA concentration was not associated with higher physical activity (Table 1), therefore higher physical activity does not explain the findings. Peak HR during exercise and HR recovery after exercise are known predictors of CVD mortality ${ }^{(9,10)}$. However, knowledge regarding the association of the long-chain $n$-3 PUFA and methylmercury with peak HR during exercise and HR recovery is lacking. As far as we know, the current study is the first population-based study to report such associations. In agreement with the lack of association between the long-chain $n$-3 PUFA and peak HR in the present study, fish oil supplementation has had no effect on peak HR during exercise among healthy men ${ }^{(18,19)}$, football players ${ }^{(20)}$ or men with history of $\mathrm{CHD}^{(21,22)}$. In contrast, in two small experimental studies, fish oil supplementation decreased peak HR during exercise test among $\operatorname{dogs}^{(23)}$ and well-trained men ${ }^{(24)}$. The lack of association in the current study and in most other studies may be explained by the fact that peak HR is determined largely by age and genetic ${ }^{(54)}$. In the experimental studies also the differences in, for example, the study setting, dosage or length of supplementation period might have had an impact on the outcome of the study. Regarding the HR recovery, a few small supplementation studies have reported a faster HR recovery after an exercise test by fish oil supplementation $^{(18,19,21,23)}$, but there are no previous population study data about the associations with the long-chain $n$-3 PUFA. More studies are needed to evaluate the impact of the long-chain $n$-3 PUFA, both from natural sources and supplements, on peak HR during exercise and HR recovery after exercise.

In the current study, EPA had a slightly stronger association with resting HR than the other long-chain $n-3$ PUFA and only 
Table 4. Heart rate (beats per min) recovery 2 min after an exercise test in quartiles of serum long-chain $n-3$ PUFA and hair mercury among 1008 men aged 42-60 from Kuopio Ischaemic Heart Disease Risk Factor Study*

(Mean values and $95 \%$ confidence intervals)

\begin{tabular}{|c|c|c|c|c|c|c|c|c|c|}
\hline & \multicolumn{6}{|c|}{ Exposure quartile } & \multirow[b]{3}{*}{$P_{\text {for trend }}$} & \multirow{2}{*}{\multicolumn{2}{|c|}{$\begin{array}{l}\text { Difference between the highest } \\
\text { and lowest quartile }\end{array}$}} \\
\hline & \multicolumn{2}{|c|}{1 (n 252) } & \multirow[b]{2}{*}{$2(n 252)$} & \multirow[b]{2}{*}{$3(n 252)$} & \multicolumn{2}{|c|}{$4(n 252)$} & & & \\
\hline & Mean & $95 \% \mathrm{Cl}$ & & & Mean & $95 \% \mathrm{Cl}$ & & Mean & $95 \% \mathrm{Cl}$ \\
\hline Total long-chain $n$-3 PUFA (\%) & & $3.26 \dagger$ & $3.26-4.01$ & $4.01-4.78$ & & .5 .39 & & & \\
\hline Model 1‡ & 39.7 & $38 \cdot 3,41 \cdot 2$ & $41 \cdot 6$ & $41 \cdot 1$ & $40 \cdot 1$ & $38 \cdot 6,41.5$ & 0.89 & 0.34 & $-1 \cdot 72,2 \cdot 41$ \\
\hline Model $2 \S$ & $39 \cdot 6$ & $38.2,41 \cdot 0$ & 41.6 & $41 \cdot 1$ & $40 \cdot 2$ & $38.8,41 \cdot 6$ & 0.76 & 0.58 & $-1.42,2.59$ \\
\hline Model 3॥ & 39.7 & $38 \cdot 3,41 \cdot 2$ & 41.6 & 41.1 & $40 \cdot 0$ & $38.6,41.5$ & 0.98 & 0.30 & $-1 \cdot 79,2 \cdot 40$ \\
\hline EPA (\%) & & 0.94 & $0.94-1.27$ & $1.27-1.66$ & & 1.66 & & & \\
\hline Model $1 \ddagger$ & $39 \cdot 1$ & $37.7,40 \cdot 6$ & 41.4 & 41.6 & $40 \cdot 3$ & $38.9,41 \cdot 8$ & 0.57 & $1 \cdot 19$ & $-0.91,3.28$ \\
\hline Model $2 \S$ & $39 \cdot 0$ & $37.5,40.4$ & $41 \cdot 2$ & $41 \cdot 6$ & $40 \cdot 8$ & $39 \cdot 3,42 \cdot 2$ & $0 \cdot 16$ & 1.79 & $-0.24,3.82$ \\
\hline Model 3॥ & 39.0 & $37.6,40.5$ & $41 \cdot 2$ & 41.6 & $40 \cdot 6$ & $39 \cdot 2,42 \cdot 1$ & 0.24 & 1.61 & $-0.49,3.72$ \\
\hline DPA (\%) & & 0.45 & $0.45-0.52$ & $0.52-0.58$ & & 0.58 & & & \\
\hline Model 1‡ & 38.4 & $37 \cdot 0,39 \cdot 9$ & 40.8 & 41.3 & $42 \cdot 0$ & $40 \cdot 6,43.5$ & 0.001 & 3.57 & $1.52,5.62$ \\
\hline Model $2 \S$ & $39 \cdot 3$ & $37.9,40.7$ & 41.0 & $40 \cdot 7$ & 41.5 & $40 \cdot 0,42 \cdot 9$ & 0.06 & $2 \cdot 14$ & $0.12,4.16$ \\
\hline Model 3॥ & 39.4 & $37.9,40 \cdot 8$ & 41.0 & 40.7 & 41.4 & $40 \cdot 0,42 \cdot 8$ & 0.08 & 2.04 & $-0.02,4.09$ \\
\hline $\mathrm{DHA}(\%)$ & & 1.73 & $1 \cdot 73-2 \cdot 19$ & $2 \cdot 19-2.59$ & & 2.59 & & & \\
\hline Model $1 \ddagger$ & 40.5 & $39 \cdot 1,42 \cdot 0$ & 41.9 & $39 \cdot 8$ & $40 \cdot 3$ & $38 \cdot 9,41 \cdot 8$ & 0.45 & -0.20 & $-2 \cdot 25,1 \cdot 86$ \\
\hline Model $2 \S$ & 40.5 & $39.1,41.9$ & 41.9 & 39.9 & $40 \cdot 2$ & $38.8,41 \cdot 6$ & 0.57 & -0.30 & $-2 \cdot 31,1 \cdot 72$ \\
\hline Model 3॥ & $40 \cdot 7$ & $39 \cdot 2,42 \cdot 1$ & 41.9 & 39.9 & $40 \cdot 0$ & $38.6,41.5$ & 0.38 & -0.64 & $-2 \cdot 73,1.45$ \\
\hline Hair Hg $(\mu \mathrm{g} / \mathrm{g})$ & & 0.36 & $0.36-0.91$ & $0.91-1.68$ & & 1.68 & & & \\
\hline Model $1 \ddagger$ & $40 \cdot 9$ & $39.4,42.4$ & $40 \cdot 3$ & $40 \cdot 7$ & $40 \cdot 7$ & $39 \cdot 2,42 \cdot 1$ & 0.99 & -0.25 & $-2 \cdot 37,1 \cdot 87$ \\
\hline Model $2 \S$ & 40.5 & $39.0,41 \cdot 9$ & $40 \cdot 0$ & $40 \cdot 6$ & 41.5 & $40 \cdot 0,42 \cdot 9$ & 0.21 & 0.98 & $-1 \cdot 11,3 \cdot 07$ \\
\hline Model 3॥ & 40.4 & $38.9,41 \cdot 8$ & $40 \cdot 1$ & $40 \cdot 6$ & 41.6 & $40 \cdot 1,43 \cdot 1$ & $0 \cdot 18$ & 1.23 & $-1.01,3.46$ \\
\hline
\end{tabular}

* The association of serum long-chain $n-3$ PUFA and hair $\mathrm{Hg}$ with heart rate recovery was analysed using ANCOVA.

$\dagger$ Medians.

$\ddagger$ Model 1 is adjusted for age and examination year.

$\S$ Model 2 is adjusted for model $1+\mathrm{BMI}\left(\mathrm{kg} / \mathrm{m}^{2}\right)$, diabetes (yes $\left./ \mathrm{no}\right)$, hypertension (yes/no), smoking (yes/no), education (years), income (euro), leisure-time physical activity $(\mathrm{kJ} /$ week (kcal/week)), intake of alcohol ( $\mathrm{g} /$ week), energy intake $(\mathrm{kJ} / \mathrm{d}(\mathrm{kcal} / \mathrm{d}))$ and blood glucose $(\mathrm{mmol} / \mathrm{l})$.

II Model 3 is adjusted for model $2+$ hair $\mathrm{Hg}$ (in analyses with fatty acids) or total long-chain $n$-3 PUFA (in analyses with $\mathrm{Hg}$ ).

DPA was associated with better HR recovery. These findings differ from our previous observations in this study population, where DHA had an inverse association with the risk of atrial fibrillation ${ }^{(5)}$ and sudden cardiac death ${ }^{(29)}$, whereas EPA or DPA were not associated with these outcomes. This suggests that the stronger inverse associations between DHA and these arrhythmic cardiac outcomes are not explained by its impact on HR in this study population. The potential mechanisms for these different associations of HR with individual fatty acids are not completely clear, although there is some data that EPA and DHA have different effects on the function of membrane ion channels in isolated human arterial myocytes. EPA may be more effective inhibitor of the voltage-gated $\mathrm{Na}^{+}$, whereas DHA mostly inhibits delayed-rectifier $\mathrm{K}^{+}$current $^{(56)}$. It has been reported that structure/function of voltage-gated $\mathrm{Na}^{+}$is related to the risk of cardiac arrhythmias ${ }^{(57)}$.

Compared with EPA and DHA, the cardioprotective and mechanistic properties of the mainly endogenously produced long-chain $n$-3 PUFA, DPA, are less well known. DPA has been found to have a similar inverse association with fatal CHD as EPA and DHA, but a stronger inverse association with total CHD risk $^{(4)}$, suggesting that DPA may also have some cardioprotective properties.

Previously in the KIHD cohort, higher hair $\mathrm{Hg}$ content has been associated with higher risk of CVD and it has also attenuated the inverse associations of the serum long-chain $n-3$ PUFA with CVD outcomes ${ }^{(29)}$. The exact mechanisms for this are not known, although, for example, reduction in the antioxidative capacity and increasing free radical stress have been suggested ${ }^{(26)}$. Because methylmercury is a neurotoxicant, it is also possible that the adverse cardiovascular effects could be explained by its effects on the autonomic nervous function ${ }^{(26)}$. However, in the current study, we did not observe an association between hair $\mathrm{Hg}$ content and resting $\mathrm{HR}$ or $\mathrm{HR}$ recovery, and adjustment for $\mathrm{Hg}$ only slightly attenuated the associations with the long-chain $n-3$ PUFA. Although we did find that higher hair $\mathrm{Hg}$ content was associated with lower peak $\mathrm{HR}$, this finding needs to be interpreted cautiously because, as mentioned, peak HR is mainly determined by age and genetics and there is no clear mechanism how $\mathrm{Hg}$ could affect peak HR, but not resting HR or HR recovery. Our result of no association with resting HR is in agreement with the previous findings from an experimental study ${ }^{(31)}$ and from two cross-sectional studies among healthy adults ${ }^{(32,33)}$. In contrast, two studies have found that higher blood methylmercury concentration was associated with increased resting HR among adults ${ }^{(34,35)}$. These conflicting results might be due to, for example, different methods for measuring the exposure to $\mathrm{Hg}$. Hair $\mathrm{Hg}$ concentration is a good marker of long-term $\mathrm{Hg}$ exposure, whereas blood $\mathrm{Hg}$ reflects relatively short-term exposure to $\mathrm{Hg}^{(26)}$.

The strengths of our study include the use of serum longchain $n$-3 PUFA and hair $\mathrm{Hg}$ as exposures instead of dietary intakes. Because serum fatty acids and hair $\mathrm{Hg}$ are objective biomarkers for exposure ${ }^{(26,58)}$, their use reduces the bias by misclassification, which would attenuate the associations towards the null. Other strengths include the extensive 
examination of potential confounders and the large number of participants with the assessment of resting and exerciseinduced HR. A potential limitation was that the participants were middle-aged and older men from Eastern Finland, so the findings may not be generalisable to other populations or to women.

In conclusion, higher circulating concentrations of the longchain n-3 PUFA were inversely associated with resting HR, a finding well supported by the previous research. As higher resting $\mathrm{HR}$ is associated with increased risk of $\mathrm{CVD}^{(5,6)}$, this result could partially explain how long-chain $n-3$ PUFA may reduce the risk of CVD. Only the minor long-chain $n-3$ PUFA, DPA, was associated with faster HR recovery and none of the fatty acids was associated with peak HR during exercise. Unlike with the associations with CVD outcomes in this study population $^{(27-29)}$, $\mathrm{Hg}$ exposure only slightly attenuated the associations of the long-chain $n-3$ PUFA with HR. This indicates that its effects on $\mathrm{HR}$ do not explain the negative impact of $\mathrm{Hg}$ exposure on CVD health in this study population. More largescale studies in diverse populations are needed to studies to confirm these findings.

\section{Acknowledgements}

The authors thank the staff of the Kuopio Research Institute of Exercise Medicine and the Research Institute of Public Health, University of Eastern Finland, for data collection.

The study was supported by Olvi Foundation, Antti and Tyyne Soininen Foundation, and Saara Kuusisto and Salme Pennanen Foundation (B. T.).

The authors' contributions were as follows: B. T., S. K., T.-P. T., K. S. and J. K. V. contributed to the conception and design of the research; S. K., and T.-P. T. acquired data; B. T. and J. K. V. analysed data and interpreted the results; B. T. drafted the manuscript; all authors critically revised the paper and approved the final version.

None of the authors has any conflicts of interest to declare.

\section{Supplementary material}

For supplementary material/s referred to in this article, please visit https://doi.org/10.1017/S0007114517003191

\section{References}

1. Feigin V (2016) Global, regional, and national life expectancy, all-cause mortality, and cause-specific mortality for 249 causes of death, 1980-2015: a systematic analysis for the Global Burden of Disease Study 2015. Lancet 388, 1459-1544.

2. Mozaffarian D \& Wu JH (2011) Omega-3 fatty acids and cardiovascular disease: effects on risk factors, molecular pathways, and clinical events. I Am Coll Cardiol 58, 2047-2067.

3. Chen GC, Yang J, Eggersdorfer M, et al. (2016) n-3 Long-chain polyunsaturated fatty acids and risk of all-cause mortality among general populations: a meta-analysis. Sci Rep 6, 28165.

4. Del Gobbo LC, Imamura F, Aslibekyan S, et al. (2016) Omega-3 polyunsaturated fatty acid biomarkers and coronary heart disease: pooling project of 19 cohort studies. JAMA Intern Med 176, 1155-1166.

5. Okamura T, Hayakawa T, Kadowaki T, et al. (2004) Resting heart rate and cause-specific death in a 16.5-year cohort study of the Japanese general population. Am Heart J 147, 1024-1032.

6. Legeai C, Jouven X, Tafflet M, et al. (2011) Resting heart rate, mortality and future coronary heart disease in the elderly: the 3C Study. Eur I Cardiovasc Prev Rehabilit 18, 488-497.

7. Savonen KP, Lakka TA, Laukkanen JA, et al. (2006) Heart rate response during exercise test and cardiovascular mortality in middle-aged men. Eur Heart J 27, 582-588.

8. Savonen K, Kiviniemi V, Laaksonen D, et al. (2011) Two-minute heart rate recovery after cycle ergometer exercise and all-cause mortality in middle-aged men.J Intern Med $\mathbf{2 7 0}$, 589-596.

9. Sandvik L, Erikssen J, Ellestad M, et al. (1995) Heart rate increase and maximal heart rate during exercise as predictors of cardiovascular mortality: a 16-year follow-up study of 1960 healthy men. Coron Artery Dis 6, 667-680.

10. Cole CR, Foody JM, Blackstone EH, et al. (2000) Heart rate recovery after submaximal exercise testing as a predictor of mortality in a cardiovascularly healthy cohort. Ann Intern Med 132, $552-555$.

11. Mozaffarian D, Geelen A, Brouwer IA, et al. (2005) Effect of fish oil on heart rate in humans: a meta-analysis of randomized controlled trials. Circulation 112, 1945-1952.

12. Dallongeville J, Yarnell J, Ducimetiere P, et al. (2003) Fish consumption is associated with lower heart rates. Circulation 108, 820-825.

13. Mozaffarian D, Prineas RJ, Stein PK, et al. (2006) Dietary fish and $n-3$ fatty acid intake and cardiac electrocardiographic parameters in humans. J Am Coll Cardiol 48, 478-484.

14. Mozaffarian D, Gottdiener JS \& Siscovick DS (2006) Intake of tuna or other broiled or baked fish versus fried fish and cardiac structure, function, and hemodynamics. Am J Cardiol 97, 216-222.

15. Ebbesson SO, Devereux RB, Cole S, et al. (2010) Heart rate is associated with red blood cell fatty acid concentration: the Genetics of Coronary Artery Disease in Alaska Natives (GOCADAN) study. Am Heart J 159, 1020-1025.

16. Valera B, Dewailly E, Anassour-Laouan-Sidi E, et al. (2011) Influence of $n-3$ fatty acids on cardiac autonomic activity among Nunavik Inuit adults. Int J Circumpolar Health 70, 6-18.

17. Valera B, Suhas E, Counil E, et al. (2014) Influence of polyunsaturated fatty acids on blood pressure, resting heart rate and heart rate variability among French Polynesians. J Am Coll Nutr 33, 288-296.

18. Macartney MJ, Hingley L, Brown MA, et al. (2014) Intrinsic heart rate recovery after dynamic exercise is improved with an increased omega-3 index in healthy males. Br J Nutr 112, 1984-1992.

19. Hingley L, Macartney M, Brown M, et al. (2014) Low dose fish oil increases the omega-3 index improving cycling efficiency and heart rate recovery. J Sci Cycling $\mathbf{3}, 41$.

20. Buckley JD, Burgess S, Murphy KJ, et al. (2009) DHA-rich fish oil lowers heart rate during submaximal exercise in elite Australian Rules footballers. J Sci Med Sport 12, 503-507.

21. O'Keefe JH, Abuissa H, Sastre A, et al. (2006) Effects of omega-3 fatty acids on resting heart rate, heart rate recovery after exercise, and heart rate variability in men with healed myocardial infarctions and depressed ejection fractions. Am J Cardiol 97, 1127-1130. 
22. Vacek J, Harris W \& Haffey K (1989) Short-term effects of omega-3 fatty acids on exercise stress test parameters, angina and lipoproteins. Biomed Pharmacother 43, 375-379.

23. Billman GE \& Harris WS (2011) Effect of dietary omega-3 fatty acids on the heart rate and the heart rate variability responses to myocardial ischemia or submaximal exercise. Am J Physiol Heart Circ Physiol 300, H2288-H2299.

24. Peoples GE, McLennan PL, Howe PR, et al. (2008) Fish oil reduces heart rate and oxygen consumption during exercise. J Cardiovasc Pharmacol 52, 540-547.

25. Ninio DM, Hill AM, Howe PR, et al. (2008) Docosahexaenoic acidrich fish oil improves heart rate variability and heart rate responses to exercise in overweight adults. Br J Nutr 100, 1097-1103.

26. Roman HA, Walsh TL, Coull BA, et al. (2011) Evaluation of the cardiovascular effects of methylmercury exposures: current evidence supports development of a dose-response function for regulatory benefits analysis. Environ Health Perspect 119, 607.

27. Virtanen JK, Voutilainen S, Rissanen TH, et al. (2005) Mercury, fish oils, and risk of acute coronary events and cardiovascular disease, coronary heart disease, and all-cause mortality in men in eastern Finland. Arterioscler Thromb Vasc Biol 25, 228-233.

28. Virtanen JK, Rissanen TH, Voutilainen S, et al. (2007) Mercury as a risk factor for cardiovascular diseases. J Nutr Biochem $\mathbf{1 8}$ 75-85.

29. Virtanen JK, Laukkanen JA, Mursu J, et al. (2012) Serum longchain $n$-3 polyunsaturated fatty acids, mercury, and risk of sudden cardiac death in men: a prospective populationbased study. PLOS ONE 7, e41046.

30. Guallar E, Sanz-Gallardo MI, Veer Pv, et al. (2002) Mercury, fish oils, and the risk of myocardial infarction. $N$ Engl J Med 347, 1747-1754

31. Yaginuma-Sakurai K, Murata K, Shimada M, et al. (2010) Intervention study on cardiac autonomic nervous effects of methylmercury from seafood. Neurotoxicol Teratol 32, 240-245.

32. Valera B, Dewailly É, Poirier P, et al. (2011) Influence of mercury exposure on blood pressure, resting heart rate and heart rate variability in French Polynesians: a crosssectional study. Environ Health 10, 99

33. Valera B, Dewailly E \& Poirier P (2011) Impact of mercury exposure on blood pressure and cardiac autonomic activity among Cree adults (James Bay, Quebec, Canada). Environ Res 111, $1265-1270$

34. Valera B, Dewailly É \& Poirier P (2013) Association between methylmercury and cardiovascular risk factors in a native population of Quebec (Canada): a retrospective evaluation. Environ Res 120, 102-108.

35. Oka T, Matsukura M, Okamoto M, et al. (2002) Autonomic nervous functions in fetal type Minamata disease patients: assessment of heart rate variability. Tohoku J Exp Med 198, 215-221.

36. Salonen JT (1988) Is there a continuing need for longitudinal epidemiologic research? The Kuopio Ischaemic Heart Disease Risk Factor Study. Ann Clin Res 20, 46-50.

37. Lakka TA, Venalainen JM, Rauramaa R, et al. (1994) Relation of leisure-time physical activity and cardiorespiratory fitness to the risk of acute myocardial infarction in men. $N$ Engl J Med 330, 1549-1554.

38. Laukkanen JA, Lakka TA, Rauramaa R, et al. (2001) Cardiovascular fitness as a predictor of mortality in men. Arch Intern Med 161, 825-831.

39. Salonen JT, Seppanen K, Nyyssonen K, et al. (1995) Intake of mercury from fish, lipid peroxidation, and the risk of myocardial infarction and coronary, cardiovascular, and any death in eastern Finnish men. Circulation 91, 645-655.

40. Salonen JT, Nyyssonen K, Korpela H, et al. (1992) High stored iron levels are associated with excess risk of myocardial infarction in eastern Finnish men. Circulation 86, 803-811.
41. James PA, Oparil S, Carter BL, et al. (2014) 2014 evidencebased guideline for the management of high blood pressure in adults: report from the panel members appointed to the Eighth Joint National Committee (JNC 8). JAMA $\mathbf{3 1 1}$, 507-520.

42. Virtanen JK, Mursu J, Tuomainen TP, et al. (2014) Dietary fatty acids and risk of coronary heart disease in men: the Kuopio Ischemic Heart Disease Risk Factor Study. Arterioscler Thromb Vasc Biol 34, 2679-2687.

43. Laaksonen D, Lakka T, Lakka H, et al. (2002) Serum fatty acid composition predicts development of impaired fasting glycaemia and diabetes in middle-aged men. Diabetic Med 19, 456-464

44. Ferguson CJ (2009) An effect size primer: a guide for clinicians and researchers. Prof Psychol Res 40, 532.

45. Reinders I, Virtanen J, Brouwer I, et al. (2012) Association of serum $n-3$ polyunsaturated fatty acids with C-reactive protein in men. Eur J Clin Nutr 66, 736-741.

46. Virtanen JK, Nyantika AN, Kauhanen J, et al. (2012) Serum long-chain $n-3$ polyunsaturated fatty acids, methylmercury and blood pressure in an older population. Hypertension Res 35, 1000-1004.

47. Tajik B, Kurl S, Tuomainen T, et al. (2017) Associations of the serum long-chain omega-3 polyunsaturated fatty acids and hair mercury with heart rate-corrected QT and JT intervals in men: the Kuopio Ischaemic Heart Disease Risk Factor Study. Eur J Nutr 56, 2319-2327.

48. Tajik B, Kurl S, Tuomainen T, et al. (2016) The association of serum long-chain $n$-3 PUFA and hair mercury with exercise cardiac power in men. BrJ Nutr 116, 487-495.

49. Kang JX \& Leaf A (1994) Effects of long-chain polyunsaturated fatty acids on the contraction of neonatal rat cardiac myocytes. Proc Natl Acad Sci U S A 91, 9886-9890.

50. Xiao Y, Sigg D \& Leaf A (2005) The antiarrhythmic effect of $n-3$ polyunsaturated fatty acids: modulation of cardiac ion channels as a potential mechanism. J Membr Biol 206, 141-154.

51. Gregoire J, Tuck S, Hughson RL, et al. (1996) Heart rate variability at rest and exercise: influence of age, gender, and physical training. Can J Applied Physiol 21, 455-470.

52. Darr KC, Bassett DR, Morgan BJ, et al. (1988) Effects of age and training status on heart rate recovery after peak exercise. Am J Physiol 254, H340-H343.

53. Thompson PD, Buchner D, Pina IL, et al. (2003) Exercise and physical activity in the prevention and treatment of atherosclerotic cardiovascular disease: a statement from the Council on Clinical Cardiology (Subcommittee on Exercise, Rehabilitation, and Prevention) and the Council on Nutrition, Physical Activity, and Metabolism (Subcommittee on Physical Activity). Circulation 107, 3109-3116.

54. Bray MS, Hagberg JM, Perusse L, et al. (2009) The human gene map for performance and health-related fitness phenotypes: the 2006-2007 update. Med Sci Sport Exerc 41, 34-72.

55. Virtanen JK, Mursu J, Voutilainen S, et al. (2009) Serum longchain $n-3$ polyunsaturated fatty acids and risk of hospital diagnosis of atrial fibrillation in men. Circulation 120, $2315-2321$

56. Li G, Sun H, Zhang X, et al. (2009) Omega-3 polyunsaturated fatty acids inhibit transient outward and ultra-rapid delayed rectifier $\mathrm{K}$ currents and $\mathrm{Na}$ current in human atrial myocytes. Cardiovasc Res 81, 286-293.

57. George AL Jr (2005) Inherited disorders of voltage-gated sodium channels. J Clin Invest 115, 1990-1999.

58. Hodson L, Skeaff CM \& Fielding BA (2008) Fatty acid composition of adipose tissue and blood in humans and its use as a biomarker of dietary intake. Prog Lipid Res 47, 348-380. 